\title{
Relationships between type of hoof lesion and behavioral signs of lameness in Holstein cows housed in Canadian tiestall facilities
}

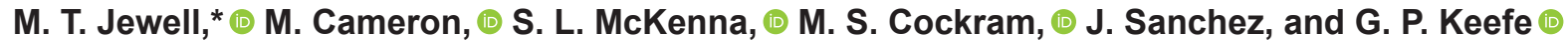 \\ Department of Health Management, Atlantic Veterinary College, University of Prince Edward Island, Charlottetown, Prince Edward Island, \\ Canada, C1A 4P3
}

\begin{abstract}
Although foot pain can affect gait, the presence of a hoof lesion may or may not cause the cow to show visible changes in their gait. This can be dependent on the type and severity of the lesion; for example, the presence of a sole ulcer (SU) has been associated with increased gait scores, whereas digital dermatitis (DD) and sole hemorrhage $(\mathrm{SH})$ have not. In tiestall facilities, gait scoring can be difficult to perform. An alternative method, known as stall lameness scoring (SLS), allows observers to assess cattle for lameness while they remain in their stall. Lameness is determined based on behavioral changes in weight bearing and foot positioning, which include: shifting weight, resting a foot, standing on the edge of the stall, and uneven weight bearing when stepping side to side. The aim of this study was to examine relationships between hoof lesions and these behavioral indicators. A total of 557 observations of SLS and corresponding hoof trimming records, collected during routine trimming events on 7 tiestall herds, were obtained. Trimming was performed by 2 trained hoof trimmers with good agreement on lesion identification, based on quizzes taken at the beginning and mid-way through the study. To ensure trimming had no effect on the behavioral indicators observed, SLS was always performed by a trained observer before trimming. Behavioral indicators focused on the hind limbs only; therefore, the analysis was confined to hind limb lesions using logistic regression to detect the presence of hoof lesion based on observations made during SLS. Seventy-five percent of observed cows had no SLS behavioral indicators, whereas, 11,12 , and $1 \%$ had 1, 2, and 3 behavioral indicators, respectively. At least one hind limb lesion was noted during trimming in 19\% of cows, with the most common lesions being DD (7\%), $\mathrm{SU}(6 \%)$, and $\mathrm{SH}(4 \%)$. A cow that was observed resting one foot and bearing weight unevenly when moving side to side had higher odds of having a hind limb hoof
\end{abstract}

Received July 19, 2019.

Accepted August 7, 2020.

*Corresponding author: mtjewell@upei.ca lesion than a cow not displaying these behaviors. When looking at specific hoof lesions, a cow observed resting one limb and bearing weight unevenly had higher odds of having a SU compared with those not displaying these behaviors. A cow observed shifting their weight from one foot to another had higher odds of having $\mathrm{SH}$, and a cow observed bearing weight unevenly had higher odds of DD. Behavioral indicators in weight bearing and foot positioning can help identify cows in tiestalls with hind limb hoof lesions. Producers could routinely observe their cattle for these indicators to assist in the identification of cows that may require treatment. This could help reduce the duration of clinical lameness through earlier intervention.

Key words: tiestall, lameness, hoof lesions

\section{INTRODUCTION}

Lameness has an effect on the welfare of dairy cattle, as it has an effect on all 5 freedoms, these being: (1) freedom from hunger and thirst, (2) freedom from discomfort, (3) freedom from pain, injury, and disease, (4) freedom to express normal behavior, and (5) freedom from fear and distress. Producers have the ability to help meet these freedoms and improve the welfare of their herd through early detection and quick treatment of lame cows (Whay and Shearer, 2017). A common cause of lameness in dairy cows (Murray et al., 1996), as well as beef cattle (Newcomer and Chamorro, 2006), swine (Wang et al., 2018), and equids (Bras and Redden, 2018), is a lesion in the hoof. If dairy producers were able to better identify cows with lesions they could be detected and treated more quickly, improving the welfare of their herd.

Previous studies have found that the presence of a hoof lesion in dairy cattle was associated with increased locomotion scores (Flower and Weary, 2006; Chapinal et al., 2009; Tadich et al., 2010; Thomsen et al., 2012) and changes in lying behavior (Chapinal et al., 2009; Ito et al., 2010; Thomsen et al., 2012). In cattle these lesions can be categorized by their etiology as noninfectious (e.g., sole ulcer) and infectious (e.g., digital dermatitis; Cramer et al., 2009; Potterton et al., 2012; 
Solano et al., 2016). In 2 Canadian studies reporting the prevalence of hoof lesions during routine hoof trimming of dairy herds, 26 to $46 \%$ of cattle had at least one hoof lesion, with differences noted between regions, facility types (i.e., freestall vs. tiestall), and herds (Cramer et al., 2008; Solano et al., 2016). Although hoof lesions are the most common cause of lameness, the type and severity of the lesion can affect whether a change in gait score will be evident. Not every cow with a hoof lesion will be classified as lame (Manske et al., 2002; Flower and Weary, 2006; Chapinal et al., 2009; Tadich et al., 2010).

Gait scoring is commonly used to identify lameness in dairy herds. However, this approach is not as simple to complete when cows are confined in tiestall facilities (Leach et al., 2009; Gibbons et al., 2014; Palacio et al., 2017). For this reason, Leach et al. (2009) developed an alternative method of lameness assessment specifically for tiestall housing, known as stall lameness scoring (SLS). Using this methodology, cows are observed for behavioral indicators of limb pain based on foot positioning and weight bearing. This methodology was later adapted by Gibbons et al. (2014) by removing the behavioral indicator of foot rotation and providing further precision to the definition of each indicator. When this adapted methodology was compared with the reference standard of gait scoring, cows with a limp were classified as lame with 59 to $68 \%$ sensitivity and 90 to $96 \%$ specificity (Gibbons et al., 2014; Palacio et al., 2017).

Several studies have investigated associations between gait scores and the occurrence of hoof lesions (e.g., Flower and Weary, 2006). However, there is no information about the relationships between the behavioral indicators assessed during SLS and the presence of hoof lesions (Gibbons et al., 2014). For this reason, the aim of the current study was to explore the relationship between behavioral indicators observed using SLS and records of hoof lesions collected during routine hoof trimming. Additionally, very few studies have reported the prevalence of hoof lesions during routine hoof trimming in tiestalls; therefore, the secondary aim of the study was to determine the prevalence of hoof lesions detected during routine trimming in tiestall facilities in the Maritime Provinces of Canada.

\section{MATERIALS AND METHODS}

\section{Study Design}

Seven hoof trimmers (HT) working in the Maritime region were invited to participate in this study, and 2 agreed to participate. Following similar methods as Cramer et al. (2008), a classroom-based training session on lesion identification was held for the participating HT in April 2016. To assess the knowledge of the HT and the interobserver agreement, a hoof lesion identification quiz was administered at the end of the training session. This quiz consisted of 16 photos of various hoof lesions presented during the training session. To ensure that the level of agreement between trimmers remained consistent, another identification quiz was administered in August 2016. This quiz consisted of 13 photos of various hoof lesions, some of which were new and some of which were included in the first quiz. Participating trimmers were asked to record any lesions that were observed during routine trimming, as well as the location within the hoof where the lesion was identified. To incentivize trimmers to continue their participation, they were offered $\$ 5 \mathrm{CDN}$ (US\$3.78) per record.

The target population for this study was tiestall herds in the Maritime Provinces of Canada. A subset of herds was selected from 34 herds that voluntarily participated in a larger cross-sectional study on lameness and were composed primarily of Holstein cattle (Jewell et al., 2019). This subset was selected because they were regular clients of the participating HT and had routine hoof trimming at least twice annually. Trimmers visited the farms between 2 and 4 times per year, trimming a substantial portion of the herd at each trimming session. When visits coincided with the visits for the larger study, cows were selected for assessment using a systematic random method (Jewell et al., 2019). During the other visits, either the whole herd or a portion of the herd selected by the producers was evaluated. Between April 2016 and April 2017, cows within each herd were assessed for lameness using the Gibbons et al. (2014) adaptation of the SLS method as previously described (Leach et al., 2009; Gibbons et al., 2014; Palacio et al., 2017). Using this method, cows were assessed for behavioral indicators of foot positioning and weight bearing while standing in their stall; these behaviors included standing with the heels of the hind limbs over the edge of the stall, continuously shifting weight between hind limbs, resting the weight of one hind limb, and bearing weight unevenly when encouraged to move side to side. The number of behavioral indicators observed was used to classify cows as lame or not (i.e., $\geq 2$ behavioral indicators = lame; Leach et al., 2009; Gibbons et al., 2014). All lameness assessments were performed live by the primary author (MJ), who had received similar training as Palacio et al. (2017) for SLS. The cows were observed undisturbed from behind for $30 \mathrm{~s}$ for the behavioral indicators described above. The cow was then encouraged to step side to side in its stall at least twice each way to assess its ability to bear weight evenly between hind limbs. These assessments were always completed before routine hoof trimming to 
avoid any behavioral indicators being associated with trimming. To ensure a high level of repeatability was achieved for this observer (kappa $\geq 0.6$ ), cows from some herds were video recorded. Intra-observer agreement was measured by comparing the scores determined live to those given while watching the video recordings 1 wk later. The intra-observer agreement was excellent, with kappa $>0.87$ for all behavioral indicators, based on 35 observations. Scores between 2 trained observers, MJ and co-author MC, were also compared for interobserver agreement on one farm. For all behavioral indicators, the interobserver agreement was excellent, with kappa $>0.89$.

During routine hoof trimming, cows were examined for the presence of hoof lesions. Each HT was required to identify the type of lesion, in accordance with International Lameness Committee (2008) definitions, and the location of this lesion on a hoof zone map (Zinpro Corporation, 2018). One HT (trimmer A), kept these records using Hoof Supervisor (KS Dairy Consulting Inc., Dresser, WI) software, whereas the other kept paper records. Because the method of assessing lameness focuses on indicators of limb pain in the hind limbs only, the focus of the hoof trimming records obtained from the HT was only on the hind limbs.

\section{Statistical Analysis}

All data were analyzed using Stata14 (StataCorp, College Station, TX). To calculate the interobserver repeatability between the $2 \mathrm{HT}$, the agreement between their answers for both lesion identification quizzes were compared using Cohen's kappa coefficient. To participate in the study, they were required to have a kappa $\geq 0.6$.

For the remainder of the analysis, the experimental unit of interest was the cow, and the outcome was the presence of any hoof lesion or a specific hoof lesion on one or both hind limbs. The main predictors of interest were the 4 behavioral indicators observed during SLS. Other predictors that could influence the outcome, such as the trimmer, season, and year, were also included in the analysis. Descriptive statistics were completed on the outcome, as well as the potential predictors. The proportion of cows with a behavioral indicator and hind limb hoof lesions was determined by dividing the number of cows with the characteristic of interest by the total number of cows observed. Using univariable random effects logistic regression the relationships between the presence of a hind limb hoof lesion and the potential predictors were explored for each specific outcome of interest. Herd was used as the random effect to account for potential clustering of lesions within herds. Predictors that were unconditionally associated
$(P \leq 0.2)$ with the lesion of interest were used in a multivariable random effects logistic regression analysis. All variables that were considered for this analysis were assessed for associations with the other variables, using chi-squared or univariable logistic regression. If 2 variables were associated $(P \leq 0.05)$, the variable that was most significantly associated with the outcome or the one that was most biologically plausible (e.g., behavior $>$ time between assessment) was added to the model. The final model for each outcome of interest was completed in a manual backward stepwise approach, removing the least significant variable $(P>0.05)$ one at a time and reintroducing them back into the model until all remaining predictors were significant $(P \leq$ $0.05)$. The models were tested for interacting variables, for example between the year and season of observation and the behavioral indicators. To determine the significance of these interactions in the model, a post hoc adjustment was made based on the number of interactions tested. Due to the low prevalence of $\mathrm{SH}$ in the population, with some herds having none reported, a generalized estimation equation model was used instead of the random effects model. The same methods for selecting predictors were used for the univariable and multivariable analysis for this outcome.

After the final models were completed, the fit and predictability of the models were assessed. The fit of the model was assessed through graphical and statistical evaluations of the residuals for normality. The predictive ability of the model was assessed by computing the sensitivity (Se), specificity $(\mathbf{S p})$, and area under the curve (AUC) as suggested by Dohoo et al. (2009). The apparent prevalence of the outcome in the study population was used as the threshold for computing the predictions used to determine Se, Sp, and AUC for each model. The predictive ability of the models was also determined based on models with only the significant behavioral indicators and compared with those with all predictors.

\section{RESULTS}

\section{Hoof Trimmers Agreement}

After in-class training on lesion identification, one HT was able to correctly identify all lesions when examined at the beginning and mid-point of the study period, whereas the other HT incorrectly identified one lesion on each assessment. Agreement was acceptable at the beginning of the study period [kappa 0.93 (95\% CI: 0.85-1.00)] and remained acceptable at the mid-point assessment [kappa 0.91 (95\% CI: 0.84-1.00)]. With these results, both HT were accepted to participate in the study. 


\section{Description of Study Population}

A total of 7 tiestall herds, 3 of which were located in New Brunswick (NB) and 4 in Prince Edward Island $(\mathrm{PE})$, were included in this study. Routine hoof trimming was completed by trimmer A for the NB herds and by trimmer B for the PE herds. Cows in each herd were assessed using SLS before hoof trimming, between 1 and 4 times throughout the study period, resulting in a total of 557 observations of behavioral indicators and corresponding hoof trimming records. There were 224 cows with single observations, 135 cows with 2 observations, and 21 cows with 3 observations, with an average of 1.4 observations per cow. As there was a limited number of cows with repeated observations, this was not accounted for in the random effects model. Table 1 outlines the distribution of when and where these observations occurred, for example, $69 \%$ of observations occurred in PE herds and $67 \%$ of hoof trimming assessments occurred within 1 wk of SLS assessments. When hoof trimming and assessments occurred between March and August, they were considered to be spring/summer observations, and those that occurred between September and February were considered fall/ winter. Seasons were grouped into these 2 categories because there were very few observations made during the summer and winter months. Herds were visited more frequently just before pasturing (April-May) and just after being removed from pastures (October-December). Sixty-one percent of the observations in this study occurred during the spring/summer months.

\section{Prevalence of Behavioral Indicators Observed During SLS and Prevalence of Hoof Lesions}

Throughout the study period, $75 \%$ of the observed cattle had no behavioral indicators. The remaining 11, 13 , and $2 \%$ displayed 1 to 3 behaviors, respectively. The most common behavioral indicator was uneven weight bearing when being moved from side to side, with $15 \%$

Table 1. Distribution of nonbehavioral factors considered as predictors of hind limb hoof lesions of nonrandomly selected observations, on 7 Maritime tiestall herds $(\mathrm{n}=557)$

\begin{tabular}{llc}
\hline Variable & Category & $\begin{array}{c}\text { Observations, } \\
\mathrm{n}(\%)\end{array}$ \\
\hline Trimmer & $\mathrm{A}$ & $170(31)$ \\
& $\mathrm{B}$ & $387(69)$ \\
Season & Spring/Summer & $340(61)$ \\
& Fall/Winter & $217(39)$ \\
Year & 2016 & $301(54)$ \\
Time between stall & 2017 & $256(46)$ \\
lameness scoring & $\leq 7 \mathrm{~d}$ & $371(67)$ \\
and hoof trimming & $8-14 \mathrm{~d}$ & $88(16)$ \\
\hline
\end{tabular}

of cows presenting with this behavioral indicator. The next most common behavioral indicator was resting one hind limb, with $13 \%$ showing this behavioral indicator. Eight percent of the cows were observed shifting their weight continuously between their hind limbs, and 5\% were observed standing on the edge of their stall.

The cow- and herd-level prevalence of hind limb hoof lesions observed during routine hoof trimming are shown in Table 2. In this table, we see that $18.7 \%$ (95\% CI: 15.5-22.2) of observed cows had a hoof lesion present on at least one hind limb and 7.7\% (95\% CI: 5.6-10.3) had lesions on both hind limbs. Looking at specific lesions, the most commonly noted was digital dermatitis (DD), with $6.8 \%$ of cows identified with this lesion. The next most common lesions were sole ulcers (SU) and sole hemorrhage $(\mathbf{S H})$, with $6.3 \%$ and $3.9 \%$ of cows identified with these lesions, respectively. Of the cows with lesions present during routine hoof trimming, 38\% had infectious lesions, $57 \%$ had noninfectious lesions, and $5 \%$ had a combination of both noninfectious and infectious lesions. Variability of the number and type of hoof lesions were observed between herds, with the within-herd prevalence of any hoof lesion on the hind limb ranging from 11 to $54 \%$.

\section{Factors Associated with the Presence of a Hoof Lesion}

The unconditional associations of the behavioral indicators observed during SLS, as well as other factors which could influence the presence of a hoof lesion, are presented in Table 3 . No variables were highly correlated, therefore, all variables that met the inclusion criteria $(P \leq 0.20)$ were considered for the final multivariable analysis of each outcome of interest.

The predictors that were statistically significant in the final multivariable analysis for any lesion, SU, DD

Table 2. Prevalence of hind limb lesions observed during routine hoof trimming of 557 observations on 7 tiestall herds in Prince Edward Island and New Brunswick, Canada

\begin{tabular}{lcc}
\hline Lesion type & $\begin{array}{c}\text { Cow-level } \\
\text { prevalence }\end{array}$ & $\begin{array}{l}\text { Within-herd } \\
\text { prevalence }^{1}\end{array}$ \\
\hline None & 81.3 & $77.5(46.3-89.1)$ \\
Any lesion & 18.7 & $22.5(10.9-53.7)$ \\
Bilateral lesion & 7.7 & $9.5(2.2-17.1)$ \\
Infectious & 8.1 & $8.7(1.9-18)$ \\
Digital dermatitis & 6.8 & $7.6(1.9-18.0)$ \\
Heel erosion & 1.1 & $0.9(0-2.4)$ \\
Noninfectious & 11.5 & $14.9(3.3-41.5)$ \\
Sole ulcer & 6.3 & $8.0(2.9-19.5)$ \\
Sole hemorrhage & 3.9 & $5.0(0-14.6)$ \\
White line disease & 1.3 & $1.8(0-9.8)$ \\
Other & 0.9 & $1.3(0-2.4)$ \\
\hline
\end{tabular}

${ }^{1}$ Mean (minimum and maximum). 
Table 3. Univariable analysis to identify significant predictors for any lesion, sole ulcer, digital dermatitis, and sole hemorrhage, on 557 observations from 401 cows

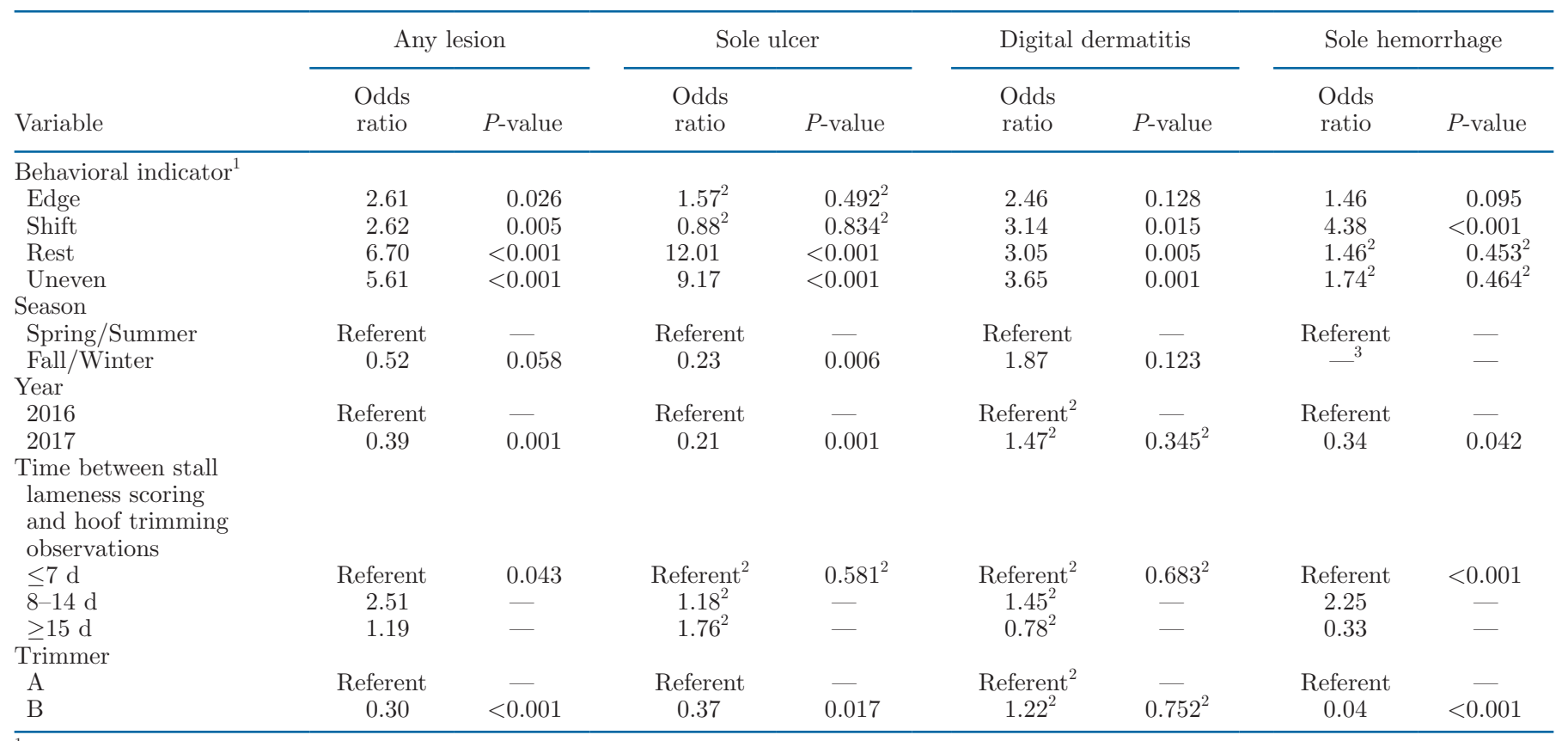

${ }^{1}$ Edge $=$ intentionally standing with the heel of one or both hind limbs over the rear edge of the stall; Shift = continuously shifting weight between hind limbs; Rest $=$ uneven weight distribution of hind limbs when standing in place; Uneven $=$ uneven weight distribution between hind limbs when stepping side to side.

${ }^{2}$ Did not meet the inclusion criteria for the multivariate analysis.

${ }^{3}$ No variation in season when sole hemorrhage was observed.

and $\mathrm{SH}$ are presented in Tables 4, 5, 6, and 7, respectively. There were 8 interactions tested per model, with none being significant in the final models. The results from each of these models show that at least one type of behavioral indicator was significantly associated with the presence of a hind limb hoof lesion. For example, in Table 5 we see that there was an association between a cow resting one hind limb and the presence of a SU in at least one hind limb. The presence of a SU was also associated with uneven weight bearing when encouraged to step side to side. Along with behavioral indicators, we found that other factors such as year, season and trimmer, were associated with the presence of hoof lesions in the hind limbs.

The predictive ability of these models is presented in Table 8 and Table 9 as the Se, Sp, and AUC. The models created in this study, in general had better $\mathrm{Sp}$ (range $77-87 \%$ ) than Se (37-86\%), giving them the ability to better identify cows without lesions. The overall accuracy of the models (i.e., AUC) of correctly classifying cows with and without lesions, as well as each specific lesion of interest, ranged from 62 to $83 \%$.

Table 4. Factors significantly associated with the presence of any lesion on 557 observations from 401 cows in the final multivariable random effects logistic regression analysis

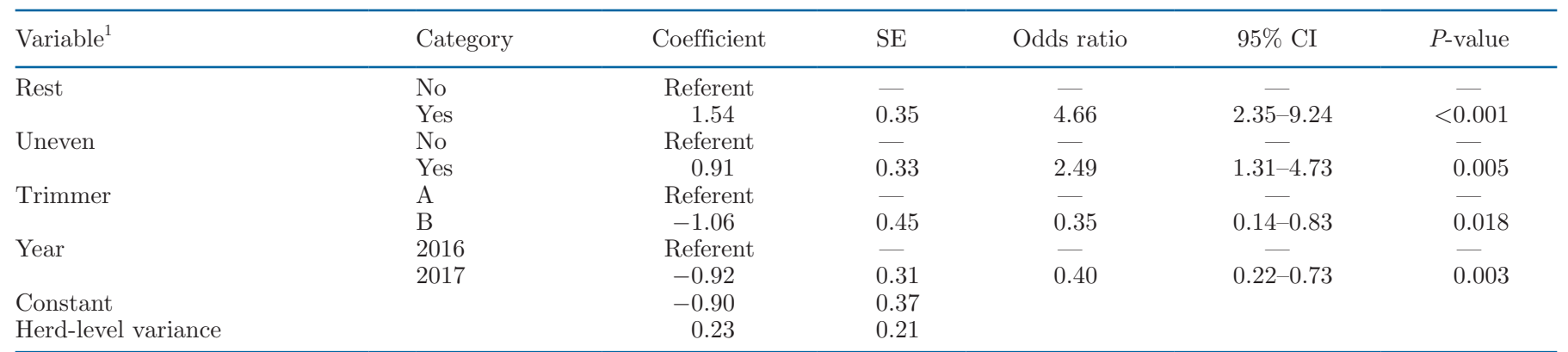

${ }^{1}$ Rest $=$ uneven weight distribution of hind limbs when standing in place; Uneven = uneven weight distribution between hind limbs when stepping side to side. 
Table 5. Factors significantly associated with the presence of sole ulcers, in the final multivariable random effects logistic regression model using 557 observations from 401 cows

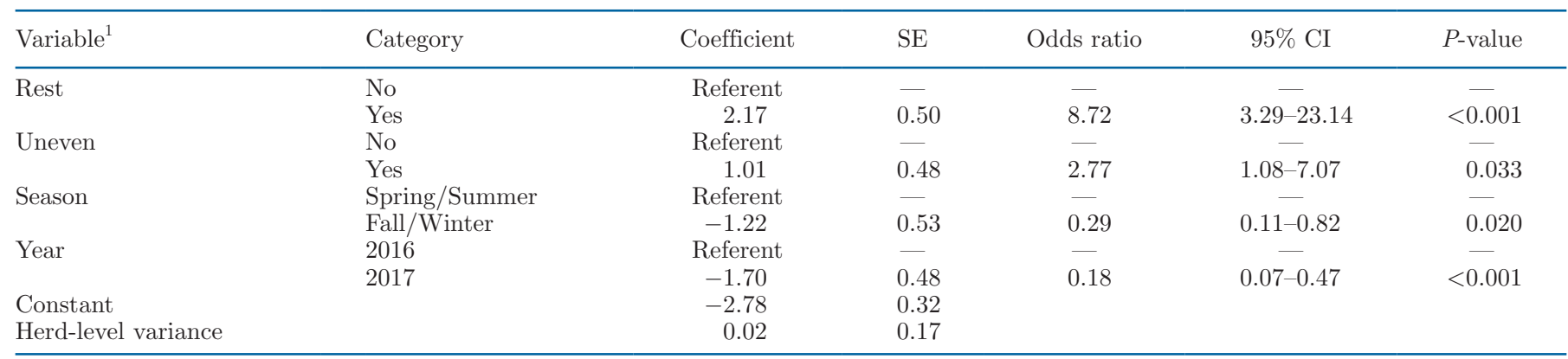

${ }^{1}$ Rest $=$ uneven weight distribution of hind limbs when standing in place; Uneven = uneven weight distribution between hind limbs when stepping side to side; between-herd variance was not statistically significant.

\section{DISCUSSION}

\section{Prevalence of Hind Limb Hoof Lesions}

The percentage of observed cows with a hoof lesion present on at least one hind limb during routine hoof trimming were comparable to a larger study in Ontario, where $24 \%$ of tiestall cattle had a hoof lesion on the hind limb (Cramer et al., 2008). The percentage of cows observed with multiple lesions was similar to the $5 \%$ previously reported by Cramer et al. (2008) and Solano et al. (2016). When looking at the type of hoof lesions based on their etiology (i.e., infectious vs. noninfectious) we found that noninfectious types of lesions were the most common, with $57 \%$ of observed lesions being classified as noninfectious. This is different than the findings of previous studies, where infectious lesions, primarily DD and $\mathrm{HE}$, were most commonly observed (Manske et al., 2002; Cramer et al., 2008; Solano et al., 2016).

In this study, not all cows were trimmed at each trimming session, particularly in herds with more frequent trimming. Producers could have selected a proportion of animals for trimming at each session based on specific criteria, such as stage of lactation or previous observation of lameness. If producers were selecting cows based on their stage of production, which has been associated with the presence of hoof lesions (Somers et al., 2005; Solano et al., 2016), or due to observation of lameness, this could lead to an overestimation of hoof lesions re- ported during this study. Five herds trimmed twice per year including all cows, whereas 2 herds trimmed a portion of herd at more frequent time periods. The specific selection criteria for the cows selected for trimming was not recorded. Additionally, the herds within the current study were not randomly selected from the target population, and they were chosen based on voluntary participation in the study, as well as their relationship with the participating HT.

\section{Associations Between Behavioral Indicators of Limb Pain and Hoof Lesions}

In the current study we hypothesized that the behavioral indicators observed during SLS were associated with the presence of a hind limb lesion. The focus was specifically on hind limb lesions because the behaviors observed during SLS focus on the hind limbs (Leach et al., 2009). Cows have limited ability to redistribute weight from their fore limbs to their hind limbs (Neveux et al., 2006) and therefore any forelimb lesions would be unlikely to cause behavioral indicators in the hind limbs.

During our study, $11 \%$ (48 out of 417 ) of observations with no recorded behavioral indicators during SLS assessment had at least one hind limb lesion. Being a prey species, cattle can be quite stoic when experiencing pain and may show no overt signs of pain until it is severe (Anil et al., 2005; Nechanitzky et al., 2016). It is possible that the lesions these cows had were at an early

Table 6. Factors significantly associated with digital dermatitis in the final multivariable random effects logistic regression analysis of 557 observations from 401 cows

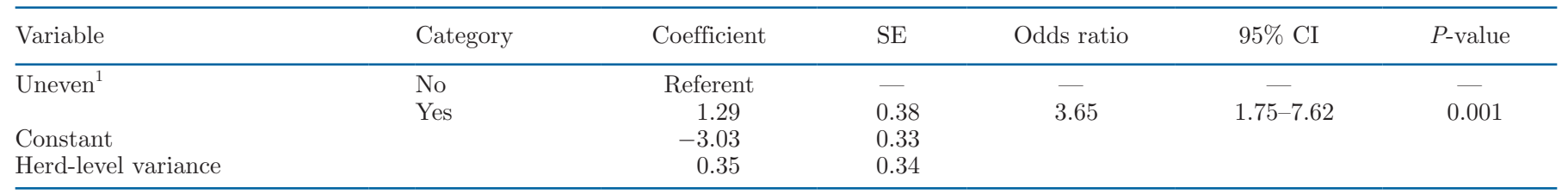

${ }^{1}$ Uneven weight distribution between hind limbs when stepping side to side. 
Table 7. Factors significantly associated with sole hemorrhage in the multivariable generalized estimation equation using 557 observations from 401 cows

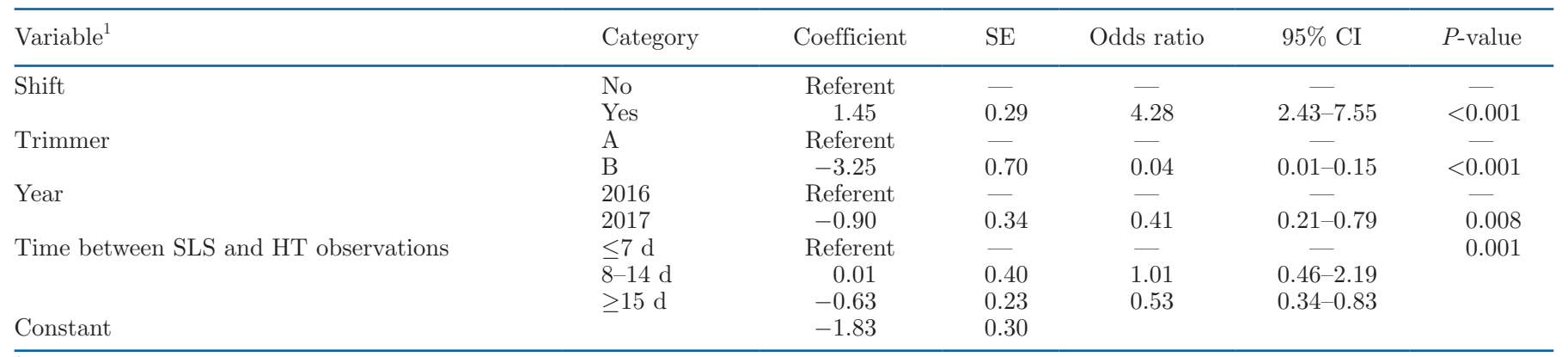

${ }^{1}$ Shift $=$ continuously shifting weight between hind limbs; SLS = stall lameness scoring; HT = hoof trimmer.

stage and not severe enough to cause sufficient pain to show overt signs to the observers. Perhaps behavioral indicators without visible lesions indicates limb pain before an observable lesion or that these cows were exhibiting behavioral indicators of limb pain due to another reason, such as joint pain or poor confirmation.

When cows did show behavioral indicators, we found that those resting a hind limb and bearing weight unevenly were more likely to have a hoof lesion on their hind limb than those not displaying these behaviors, as shown in Table 3. When using 2 or more behavioral indicators of limb pain, Palacio et al. (2017) found that 90 and $97 \%$ of cows classified as lame were resting a hind limb and bearing weight unevenly, respectively. For this reason, it is not unexpected that these 2 behaviors would be more likely to be observed when a lesion was present, as hoof lesions are the principal reason for cows to appear lame (Murray et al., 1996; Newcomer and Chamorro, 2016).

When looking at specific hoof lesions, cows that were resting a hind limb and bearing weight unevenly were also more likely to have a SU than those not displaying these behaviors. Previous studies focusing on locomotion scoring in association with hoof lesions have found that $\mathrm{SU}$ was associated with an increase in gait score, indicative of a greater severity of lameness (Flower and Weary, 2006; Chapinal et al., 2009; Tadich et al., 2010). Because we know resting a limb and uneven weight bearing are the most common behaviors exhibited by lame cows (Palacio et al., 2017), these results are not unexpected. The presence of a SU can be painful for the animal, resulting in longer lying bouts and total lying times, as these animals are more reluctant to stand (Chapinal et al., 2009). The pain associated with this type of lesion could explain why they are more reluctant to bear weight evenly and fully on the effected limb.

We found that cows that bear weight unevenly were more likely to have DD on at least one hind limb. In previous studies, no significant associations between DD and increased gait scores have been found (Chapinal et al., 2009; Tadich et al., 2010). Herds with a high prevalence of DD also have a higher prevalence of lameness at the herd level; however, at the individual cow level, not all cows with DD appear lame (Berry, 2001). The lesions of DD can be differentiated based on their macroscopic appearance, which aids in defining the infection as active, chronic, chronic active, or healing (International Lameness Committee, 2008; Berry et al., 2012). When these lesions are in their active stages, applied pressure to the lesion can result in a pain response (Cutler et al., 2013). Although the stage of the lesion was not recorded in our study, perhaps those that were bearing weight unevenly in our study had lesions in an active or chronic active stage, which could be more likely to elicit a pain response. In future studies, it would be recommended to distinguish the stage of the lesion to determine whether the behavioral indicators observed can help determine the stage and better identify those cows that require treatment.

In our study we found that cows that were shifting their weight were more likely to have $\mathrm{SH}$ on at least one hind limb than those not shifting their weight. In previ-

Table 8. Predictive ability of models to identify cows with hind limb hoof lesions

\begin{tabular}{lcccc}
\hline Outcome & Threshold $(\%)^{1}$ & Sensitivity $(\%)$ & Specificity $(\%)$ & $\begin{array}{c}\text { Area under } \\
\text { curve }\end{array}$ \\
\hline Lesion & 19 & 62 & 82 & 0.72 \\
Sole ulcer & 6 & 63 & 87 & 0.03 \\
Digital dermatitis & 7 & 37 & 86 & 0.04 \\
Sole hemorrhage & 4 & 86 & 77 & 0.62 \\
\hline
\end{tabular}

${ }^{1}$ Threshold determined based on the apparent prevalence of the specific outcome of interest within the study population. 
Table 9. Predictive ability of models to identify cows with hind limb hoof lesions with stall lameness scoring behaviors only

\begin{tabular}{|c|c|c|c|c|c|c|}
\hline Outcome & $\begin{array}{l}\text { Significant } \\
\text { behavioral } \\
\text { indicators }\end{array}$ & Threshold $(\%)^{2}$ & Sensitivity (\%) & Specificity (\%) & $\begin{array}{l}\text { Area under } \\
\text { curve }\end{array}$ & $\mathrm{SE}$ \\
\hline Lesion & Rest and uneven & 19 & 48 & 87 & 0.67 & 0.03 \\
\hline Digital dermatitis & Uneven & 7 & 37 & 86 & 0.62 & 0.04 \\
\hline Sole hemorrhage & Shift & 4 & 32 & 92 & 0.62 & 0.05 \\
\hline
\end{tabular}

${ }^{1}$ Rest $=$ uneven weight distribution of hind limbs when standing in place; Uneven = uneven weight distribution between hind limbs when stepping side to side; Shift = continuously shifting weight between hind limbs.

${ }^{2}$ Threshold determined based on the apparent prevalence of the specific outcome of interest within the study population.

ous literature in dairy cattle, an association between gait scores and the presence of $\mathrm{SH}$ has not been identified (Flower and Weary, 2006; Chapinal et al., 2009; Tadich et al., 2010), perhaps because this lesion is variable in the amount of pain it causes compared with other noninfectious lesions, such as SU. Because SH can be considered as a subclinical lesion of other noninfectious lesions (Shearer and van Amstel, 2017), it is possible that observation of cows shifting their weight could be used to identify cows with these lesions. This would allow earlier intervention for these cows, possibly reducing the likelihood of these cows developing more severe lesions and becoming clinically lame. With a low prevalence of $\mathrm{SH}$ in our study population, the probability of correctly classifying cows having SH with our model may be affected. For this reason, would be ideal to repeat the study on a larger scale to confirm these results.

\section{Other Factors Associated with Hoof Lesions}

Along with the behavioral indicators noted above, other factors were found to be associated with the presence of hoof lesions. One of these factors was the trimmer, where 1 of the 2 trimmers was significantly more likely to report SH. Other studies have reported high variability between HT when reporting SH (Holzhauer et al., 2006; Cramer et al., 2009; Kujala et al., 2010). In our study, the trimmers used different recording techniques (electronic vs. paper), and it is possible that the trimmer with the higher reporting rate was more likely to report the mild lesions because of ease in the electronic records system.

When focusing on $\mathrm{SU}$, we also found that cows observed during the fall and winter months were less likely to have this type of lesion present, in agreement with previous studies (Sanders et al., 2009). The majority of the spring/summer trimming events occurred just before the cows going to pasture for the summer, therefore, the seasonal effect could be a result of the environment during winter housing. Cook and Nordlund (2009), noted that there are many aspects of facility design that have been associated with hoof lesions.
Although some management and environmental factors were measured for the larger study (Jewell et al., 2019), many of these measurements were on dynamic variables that could potentially change throughout our study period. As these measurements were obtained only once throughout the study period, they were not used in the current study; however, it is possible that the results in the current study are affected by these factors. In the future, measurement of different environmental and management factors could be taken at each visit to determine their relationship with the presence of hoof lesions and behavioral indicators of limb pain.

The length of time between the SLS assessment and hoof trimming was significant only for the SH model. A cow trimmed within 1 wk of SLS had 1.89 times the odds to be identified with $\mathrm{SH}$ compared with a cow trimmed 3 weeks or more after SLS. When the observations of SLS and trimming are close together, we are more likely to see the most accurate representation of what is going on in the hoof at that time. A cow identified with SH within 1 wk of SLS observations could be showing the contusion-type injuries to the sole, which can then progress to other noninfectious lesions, such as SU and white line disease, within 8 to 12 weeks (Shearer and van Amstel, 2017). Perhaps when there is a longer period of time between SLS and trimming, some lesions were still in development and were not visible. It has also been shown that mild to moderate lesions can heal in 21 to $30 \mathrm{~d}$ (Shearer and van Amstel, 2017). Perhaps when a cow was trimmed 3 or more weeks after SLS, the lesion was healed, and therefore, nothing was identified. These findings could explain why 84 observations $(15 \%)$ had at least one behavioral indicator but no hoof lesion was identified. It would have been beneficial to have multiple observations over time to determine if these cows presented with lesions at a later date.

\section{Predictive Ability of Final Multivariable Analysis}

To determine the usefulness of the models to identify cows with specific hoof lesions, the predictive ability of 
the models with all predictors considered was examined, as seen in Table 8. When looking at the overall accuracy of the models, the models correctly identified cows with and without a lesion 62 to $83 \%$ of the time, depending on the lesion type. The models had a good ability to identify cows without lesions, with specificities ranging from 77 to $87 \%$. When looking at the ability of the models to identify cows with lesions, we found that the sensitivities of the models varied from 37 to $86 \%$.

The predictive ability of the models was also examined for the models considering only the significant behavioral indicators, as shown in Table 9. As the only significant predictor for DD was uneven weight bearing, the predictive ability of this model was unchanged. When looking at the models for any lesion and SU, the Se, Sp, and AUC varied slightly, but overall Sp remained high for these models. On the other hand, in the model for $\mathrm{SH}$ when only considering the predictor of shifting weight, the Se is greatly decreased, suggesting that this particular lesion will depend on other factors, such as the trimmer's lesion identification, year (surrogate of the prevalence of $\mathrm{SH}$ ), and the time between SLS and trimming when classifying a cow with SH. Finally, none of the predictors assessed were significant for the DD model; therefore, the predictive ability remains the same in Table 8 and 9. The low predictability for DD could be because the stage and severity of this lesion were not assessed. Overall the models with only behavioral indicators have a lower predictive ability, with lower AUC, suggesting that other herd-level or cow-level factors should be considered to help correctly classify cows as having a lesion or not. The behavioral indicators themselves are significantly associated with the presence of hind limb lesions and therefore, may be of value in conjunction with other decision methods to identify which cows would require treatment.

\section{Study Limitations}

This study presented with a few limitations, one of which was the size of the study population. This small sample size is mostly due to a low response for participation from the local HT, with only 2 taking part in the study. Even though the response rate for participation was low, we do not believe there would be a response bias within our study, as the main predictors of interest (i.e., behavioral indicators of limb pain) are not associated with the HT. The small sample size and low prevalence of some lesions within the study population could also effect the predictive ability of these models. For these reasons, it is recommended that this study be repeated within a larger population.
Another major limitation with the study was that more information about the cows and environment was not available for every visit. As the main objective of this project was to provide insight on the ability to detect lesions based on behavioral indicators of limb pain, information about DIM, parity, and environment were not collected routinely. It is possible that this type of data could help improve the predictive ability of the models and would be recommended to use in future studies.

\section{CONCLUSIONS}

In the current study, we found that behavioral indicators of limb pain, such as resting a limb, shifting weight between limbs, and bearing weight unevenly, are associated with the presence of a hind limb hoof lesion. Using this method of detecting lameness in dairy cattle may be beneficial for producers, veterinarians, and hoof trimmers, to aid in identifying cows that may require treatment. Prospective longitudinal studies would be valuable to determine temporal relationships between these behavioral indicators and the presence of a hoof lesion.

\section{ACKNOWLEDGMENTS}

This research is supported in main part by Agriculture and Agri-Food Canada (Ottawa, ON, Canada), and by additional contributions from Dairy Farmers of Canada (Ottawa, ON, Canada), the Canadian Dairy Network (Guelph, ON, Canada), and the Canadian Dairy Commission under the Agri-Science Clusters Initiative (Ottawa, ON, Canada). Additional funding was provided by the Sir James Dunn Animal Welfare Centre (Charlottetown, PE). As per the research agreement, aside from providing financial support, the funders have no role in the design and conduct of the studies, data collection, and analysis or interpretation of the data. Researchers maintain independence in conducting their studies, own their data, and report the outcomes regardless of the results. The decision to publish the findings rests solely with the researchers. We thank the technicians and students from Maritime Quality Milk (Charlottetown, PE, Canada) for their work collecting the data and Valacta (Sainte-Anne-de-Bellevue, QC, Canada) for the use of their production records. The authors have not stated any conflicts of interest.

\section{REFERENCES}

Anil, L., S. S. Anil, and J. Deen. 2005. Pain detection and amelioration in animals on the farm: Issues and options. J. Appl. Anim. Welf. Sci. 8:261-278. https://doi.org/10.1207/s15327604jaws0804_3. 
Berry, S. L. 2001. Diseases of the digital soft tissues. Vet. Clin. North Am. Food Anim. Pract. 17:129-142. https://doi.org/10.1016/ S0749-0720(15)30058-X.

Berry, S. L., D. H. Read, T. R. Famula, A. Mongini, and D. Döpfer. 2012. Long-term observations on the dynamics of bovine digital dermatitis lesions on a California dairy after topical treatment with lincomycin HCl. Vet. J. 193:654-658. https://doi.org/10 $.1016 / j . t v j 1.2012 .06 .048$.

Bras, R. J., and R. Redden. 2018. Understanding the basic principles of podiatry. Vet. Clin. North Am. Equine Pract. 34:391-407. https: //doi.org/10.1016/j.cveq.2018.04.015.

Chapinal, N., A. M. de Passillé, D. M. Weary, M. A. G. von Keyserlingk, and J. Rushen. 2009. Using gait score, walking speed, and lying behavior to detect hoof lesions in dairy cows. J. Dairy Sci. 92:4365-4374. https://doi.org/10.3168/jds.2009-2115.

Cook, N. B., and K. V. Nordlund. 2009. The influence of the environment on dairy cow behavior, claw health and herd lameness dynamics. Vet. J. 179:360-369. https://doi.org/10.1016/j.tvjl.2007 .09 .016 .

Cramer, G., K. D. Lissemore, C. L. Guard, K. E. Leslie, and D. F. Kelton. 2008. Herd- and cow-level prevalence of foot lesions in Ontario dairy cattle. J. Dairy Sci. 91:3888-3895. https://doi.org/ 10.3168/jds.2008-1135.

Cramer, G., K. D. Lissemore, C. L. Guard, K. E. Leslie, and D. F. Kelton. 2009. Herd-level risk factors for seven different foot lesions in Ontario Holstein cattle housed in tie stalls or free stalls. J. Dairy Sci. 92:1404-1411. https://doi.org/10.3168/jds.2008-1134.

Cutler, J. H., G. Cramer, J. J. Walter, S. T. Millman, and D. F. Kelton. 2013. Randomized clinical trial of tetracycline hydrochloride bandage and paste treatments for resolution of lesions and pain associated with digital dermatitis in dairy cattle. J. Dairy Sci. 96:7550-7557. https://doi.org/10.3168/jds.2012-6384.

Dohoo, I., W. Martin, and H. Stryhn. 2009. Veterinary Epidemiologic Research. 2nd ed. VER Inc. Charlottetown, PE, Canada.

Flower, F. C., and D. M. Weary. 2006. Effect of hoof pathologies on subjective assessments of dairy cow gait. J. Dairy Sci. 89:139-146. https://doi.org/10.3168/jds.S0022-0302(06)72077-X.

Gibbons, J., D. B. Haley, J. Higginson Cutler, C. Nash, J. Zaffino Heyerhoff, D. Pellerin, S. Adam, A. Fournier, A. M. de Passillé, J. Rushen, and E. Vasseur. 2014. Technical note: A comparison of 2 methods of assessing lameness prevalence in tiestall herds. J. Dairy Sci. 97:350-353. https://doi.org/10.3168/jds.2013-6783.

Holzhauer, M., C. J. M. Bartels, B. H. P. van den Borne, and G. van Schaik. 2006. Intra-class correlation attributable to claw trimmers scoring common hind-claw disorders in Dutch dairy herds. Prev. Vet. Med. 75:47-55. https://doi.org/10.1016/j.prevetmed.2006.01 .013 .

International Lameness Committee. 2008. Dairy claw lesion identification. In Proc. 15th Int. Symp. 7th Conf. Lameness in Ruminants, Kuopio, Finland. Savonia University of Applied Sciences, Kuopio, Finland.

Ito, K., M. A. G. von Keyserlingk, S. J. LeBlanc, and D. M. Weary. 2010. Lying behavior as an indicator of lameness in dairy cows. J. Dairy Sci. 93:3553-3560. https://doi.org/10.3168/jds.2009-2951.

Jewell, M. T., M. Cameron, J. Spears, S. L. McKenna, M. S. Cockram, J. Sanchez, and G. P. Keefe. 2019. Prevalence of lameness and associated risk factors on dairy farms in the Maritime Provinces of Canada. J. Dairy Sci. 102:3392-3405. https://doi.org/10.3168/jds .2018-15349.

Kujala, M., I. R. Dohoo, and T. Soveri. 2010. White-line disease and haemorrhages in hooves of Finnish dairy cattle. Prev. Vet. Med. 94:18-27. https://doi.org/10.1016/j.prevetmed.2009.12.006.

Leach, K. A., S. Dippel, J. Huber, S. March, C. Winckler, and H. R. Whay. 2009. Assessing lameness in cows kept in tie-stalls. J. Dairy Sci. 92:1567-1574. https://doi.org/10.3168/jds.2008-1648.

Manske, T., J. Hultgren, and C. Bergsten. 2002. Prevalence and interrelationships of hoof lesions and lameness in Swedish dairy cows. Prev. Vet. Med. 54:247-263. https://doi.org/10.1016/S0167 $-5877(02) 00018-1$.

Murray, R. D., D. Y. Downham, M. J. Clarkson, W. B. Faull, J. W. Hughes, F. J. Manson, J. B. Merritt, W. B. Russell, J. E. Sutherst, and W. R. Ward. 1996. Epidemiology of lameness in dairy cattle: Description and analysis of foot lesions. Vet. Rec. 138:586-591. https://doi.org/10.1136/vr.138.24.586.

Nechanitzky, K., A. Starke, B. Vidondo, H. Müller, M. Reckardt, K. Friedli, and A. Steiner. 2016. Analysis of behavioural changes in dairy cows associated with claw horn lesions. J. Dairy Sci. 99:2904-2914. https://doi.org/10.3168/jds.2015-10109.

Neveux, S., D. M. Weary, J. Rushen, M. A. G. von Keyserlingk, and A. M. de Passillé. 2006. Hoof discomfort changes how dairy cattle distribute their weight. J. Dairy Sci. 89:2503-2509. https://doi.org/ 10.3168/jds.S0022-0302(06)72325-6.

Newcomer, B. W., and M. F. Chamorro. 2016. Distribution of lameness lesions in beef cattle: A retrospective analysis of 745 cases. Can. Vet. J. 57:401-406.

Palacio, S., L. Peignier, C. Pachoud, C. Nash, S. Adam, R. Bergeron, D. Pellerin, A. M. de Passillé, and J. Rushen., DHaley, T. J., DeVries, and E. Vassuer. 2017. Technical note: Assessing lameness in tie-stalls using live stall lameness scoring. J. Dairy Sci. 100:6577-6582. https://doi.org/10.3168/jds.2016-12171.

Potterton, S. L., N. J. Bell, H. R. Whay, E. A. Berry, O. C. D. Atkinson, R. S. Dean, D. C. J. Main, and J. N. Huxley. 2012. A descriptive review of the peer and non-peer reviewed literature on the treatment and prevention of foot lameness in cattle published between 2000 and 2011. Vet. J. 193:612-616. https://doi.org/10 .1016 /j.tvjl.2012.06.040.

Sanders, A. H., J. K. Shearer, and A. De Vries. 2009. Seasonal incidence of lameness and risk factors associated with thin soles, white line disease, ulcers and sole punctures in dairy cattle. J. Dairy Sci. 92:3165-3174.

Shearer, J. K., and S. R. van Amstel. 2017. Pathogenesis and treatment of sole ulcers and white line disease. Vet. Clin. North Am. Food Anim. Pract. 33:283-300. https://doi.org/10.1016/j.cvfa .2017.03.001.

Solano, L., H. W. Barkema, S. Mason, E. A. Pajor, S. J. LeBlanc, and K. Orsel. 2016. Prevalence and distribution of foot lesions in dairy cattle in Alberta, Canada. J. Dairy Sci. 99:6828-6841. https://doi .org/10.3168/jds.2016-10941.

Somers, J. G. C. J., K. Frankena, E. N. Noordhuizen-Stassen, and J. H. M. Metz. 2005. Risk factors for interdigital dermatitis and heel erosion in dairy cows kept in cubicle houses in The Netherlands. Prev. Vet. Med. 71:23-34. https://doi.org/10.1016/j.prevetmed .2005.05.001.

Tadich, N., E. Flor, and L. Green. 2010. Associations between hoof lesions and locomotion score in 1098 unsound dairy cows. Vet. J. 184:60-65. https://doi.org/10.1016/j.tvjl.2009.01.005.

Thomsen, P. T., L. Munksgaard, and J. T. Sørensen. 2012. Locomotion scores and lying behaviour are indicators of hoof lesions in dairy cows. Vet. J. 193:644-647. https://doi.org/10.1016/j.tvjl 2012.06.046.

Wang, C., J.-L. Li, H.-K. Wei, Y.-F. Zhou, J.-J. Tan, H.-Q. Sun, S.-W. Jiang, and J. Peng. 2018. Analysis of influencing factors of boar claw lesion and lameness. Anim. Sci. J. 89:802-809. https://doi .org/10.1111/asj.12974.

Whay, H. R., and J. K. Shearer. 2017. The impact of lameness on welfare of the dairy cow. Vet. Clin. North Am. Food Anim. Pract. 33:153-164. https://doi.org/10.1016/j.cvfa.2017.02.008.

Zinpro Corporation. 2018. Dairy claw lesion identification. Accessed on Nov. 11, 2018. https://www.zinpro.com/lameness/dairy/lesion -identification.

\section{ORCIDS}

M. T. Jewell ๑ https://orcid.org/0000-0002-1197-3786 M. Cameron (1) https://orcid.org/0000-0003-4883-8374 S. L. McKenna ๑ https://orcid.org/0000-0002-9699-1464 M. S. Cockram @ (๑) https://orcid.org/0000-0003-3017-8996 G. P. Keefe @ https://orcid.org/0000-0003-2356-7344 